\title{
A Review of Factors Relating to Medication Non-Adherence in Patients with Schizophrenia
}

\author{
Soontareeporn Meepring ${ }^{1}$, Phatcharapon Tulyakul ${ }^{2}$, Ghunyanutt Sathagathonthun ${ }^{1} \&$ Jaruwan Supasri $^{2}$ \\ ${ }^{1}$ Department of Nursing, Faculty of Nursing, Naresuan University, Phitsanulok, Thailand \\ ${ }^{2}$ Borommarajonani College of Nursing, Trang, Thailand \\ Correspondence: Soontareeporn Meepring, Department of Nursing, Faculty of Nursing, Naresuan University, \\ Phitsanulok, Thailand.
}

Received: July 25, 2021 Accepted: August 31, 2021 Online Published: September 3, 2021

doi:10.5539/gjhs.v13n10p52

URL: https://doi.org/10.5539/gjhs.v13n10p52

\begin{abstract}
Schizophrenia is a severe chronic mental illness affecting twenty million people worldwide. Although the incidence of schizophrenia remains low, its prevalence may remain high due to medication non-adherence. Knowing potential factors relating to non-adherence with medication among patients with schizophrenia by investigating existing literature is needed in order to understand the phenomenology of this situation. Therefore, the study aimed to explore the most common factors that affected medication non-adherence in patients with schizophrenia. A systematic review was conducted through a literature search on Cochrane Database of Systematic Reviews, MEDLINE, PsycINFO, EBSCOhost, CINAHL Complete, ERIC, and Allied Health databases published from 1980 to 2021. Database searches were conducted with the terms "non-adherence to medication" "schizophrenia," and "factors." Eighty-six articles were found following the first-round search. Then seventy-eight articles were excluded due to irrelevant and duplicate tiles. Only eight articles were included for the final review. Per the findings, factors associated with medication non-adherence were categorized into four main themes: individual characteristics, cognitive appraisal, social influence, and health-care service. To improve medication adherence rates in patients with schizophrenia, psychiatric nurses must consider these specific factors while establishing nursing interventions.
\end{abstract}

Keywords: non-adherence, systematic review, schizophrenia, factors

\section{Introduction}

\subsection{Introduce the Problem}

Antipsychotic medication non-adherence is one of the greatest challenges in psychiatric mental health (Tareke, Tesfaye, Amare, Belete, \& Abate, 2018; Velligan, Sajatovic, Hatch, Kramata, \& Docherty, 2017). In term of medication, non-adherence refers to the situation that a person intentional or unintentional to take prescribed medication due to failing to refill a prescription, discontinue a medication, take the wrong dosage of medication, or take a dose at the wrong time (Ansah, Bamfo, \& Nkyi, 2021; Chukwujekwu \& Adesokun, 2017). Medication non-adherence not only increaseincreases not only the relapse rate, but also re-hospitalization, longer hospital length of stay, and attempted suicide (Sigrúnarson, Gråwe, Lydersen, \& Morken, 2017; Tareke et al., 2017; Velligan et al., 2017). Moreover, non-adherence to medication reflects the effectiveness of health-care services provided by health-care providers (Chukwujekwu \& Adesokun, 2017). Since health-care providers fail to detect whether patients adhere to medical regimens, psychiatric patients' morbidity and mortality rates, including the economic burden of the mental health-care system, tend to rise (Ansah et al., 2021; Chukwujekwu \& Adesokun, 2017).

Schizophrenia is one of the top five mental disorders across the world (World Health Organization [WHO], 2019). Almost two-third of patients with schizophrenia did not receive appropriate mental care, and ninety percent of those lived in low- and middle-wage countries (WHO, 2019). Thailand is an upper-middle-income country that has a high incidence of schizophrenia (Department of Mental Health, 2019). The Ministry of Public Health, Thailand established the national mental health plan in order to promote the percentage of patients with schizophrenia who can access and receive psychiatric treatment and care (Department of Mental Health, 2019). Even though the number of patients with schizophrenia who can access psychiatric services increases continually, approximately 
three-fourths of those did not adhere to the treatment regimens (Department of Mental Health, 2019; Suntarowit, Wijitphanya, \& Inkunthum, 2020). Similarly, over 70 percent of patients with schizophrenia in America did not adhere to medication (Desai \& Nayak, 2019).

Medication non-adherence in this patient group was such a significant and complex problem that it had an impact on the increasing relapse, comorbidity, and mortality rates (Desai \& Nayak, 2019; WHO, 2019). Patients who stopped taking medication for any reason were more likely to have a second episode of schizophrenia and suffer from other mental and physical disorders (Desai \& Nayak, 2019; WHO, 2019). Those who had schizophrenia relapse were at higher risk for cardiovascular disease, diabetes, and chronic obstructive pulmonary disease (Desai \& Nayak, 2019; WHO, 2019). Therefore, the percentage of mortality rate in these particular patients was two times higher than those who adhere to medication (Desai \& Nayak, 2019; WHO, 2019). Medication non-adherence in patients with schizophrenia was reported when patients incomplete and discontinued took medication regimens as well as missed the first-outpatient appointment and dropped out of follow-up appointments (Saengpak, Tungpunkom, \& Kitsumban, 2020; Suntarowit et al., 2020). In order to understand this phenomenon, factors relating to medication non-adherence among patients with this disease must be explored. Knowing specific characteristics associated with medication non-adherence in these patients would allow nurses to identify patients who may be at risk for medication adherence. Moreover, nurses can design effective interventions to prevent antipsychotic medication non-adherence by diminishing preventable factors.

\subsection{Objective}

The current systematic review aimed to identify significant factors associating with medication non-adherence in patients with schizophrenia. In order to conduct a literature review, the research question was established on what factors were related to medication non-adherence in this particular patient group.

\subsection{Theoretical framework}

Medication non-adherence is such a multidimensional problem influenced by many possible factors. The A Steps model of Holly, Salmond, and Saimbert (2017) lent itself well to frame research processes. Based on the foundations of the A Steps model, four steps, ask, acquire, appraise, and apply, were used to generate a conceptual framework to explore the most common factors affecting medication non-adherence in patients with schizophrenia (see Figure 1).

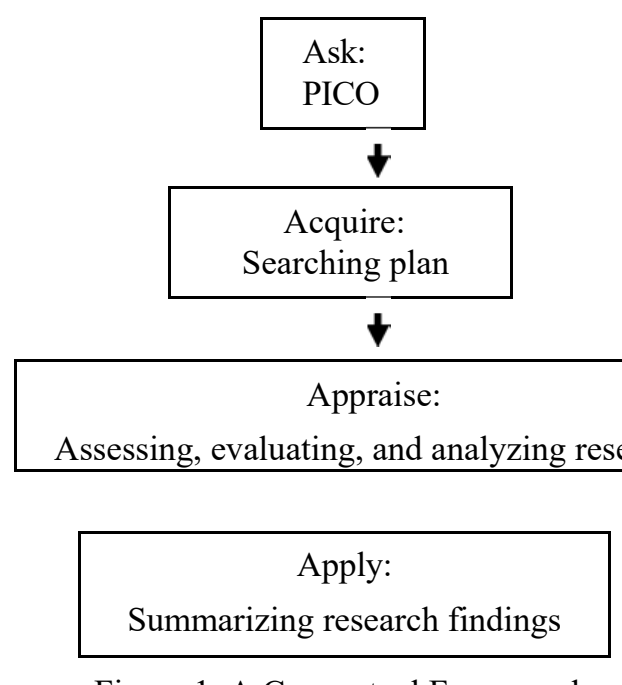

Figure 1. A Conceptual Framework

\section{Method}

\subsection{Search Strategy}

A search plan was established regarding the PICO question, databases, timeframe, keywords, and findings, as well as inclusion and exclusion criteria. In terms of the PICO question, this study aimed to reveal what factors are associated with medication non-adherence in schizophrenia patients? The combinations of keywords, including the terms: factors, medication non-adherence or non-adherence to medication, and schizophrenia, were used to search electronic data published on Cochrane Database of Systematic Reviews, MEDLINE, PsycINFO, 
EBSCOhost, CINAHL Complete, ERIC, and Allied Health databases published in English from 1980 to 2021. The first-round searching was limited to full-text articles on peer-reviewed journals. References were scanned to locate additional relevant publications.

\subsection{Inclusion and Exclusion Criteria}

Each researcher screened the second round of searching by determining article titles and reading the abstracts thoroughly. When disagreement arose, a third and fourth reviewer was consulted before making a final decision. The papers that matched the eligibility criteria were retrieved. Articles were included if they were written in English and were downloadable full-text articles on peer-reviewed journals. Research article titles on medication non-adherence in schizophrenia patients were prioritised selection. While article titles relating to other mental and psychotic disorders were excluded. Even though searching keywords did not present in the article titles, abstracts were used to indicate the relevant articles. Both quantitative and qualitative study designs were included for the review. However, duplicate articles were excluded from the chosen articles. A summary of the search strategy was depicted in Table 1.

Table 1. Seach Strategy

\begin{tabular}{llc}
\hline Search Keywords & Database & Number of articles \\
\hline & PsycINFO & 31 \\
& MEDLINE & 30 \\
(factors) AND (medication non-adherence OR & CINAHL Complete & 12 \\
non-adherence to medication) AND (schizophrenia) & EBSCOhost & 13 \\
& Cochrane Database of & 0 \\
& Systematic Reviews & 0 \\
\hline Total articles & ERIC & \\
Total abstract and titles reviewed & 86 & \\
Total articles after excluded irrelevant and duplication & 8 & \\
\hline
\end{tabular}

\subsection{Data Extraction}

All studies that met the relevant criteria were retained for the data extraction stage of the review process. Data extraction form was developed to summarize data in terms of authors, year of publication, country, research design, samples, and research findings.

\subsection{Quality Assessment}

The strength of the studies will be an important feature because if any studies have an effect on the assessment and process of search strategies, then the result will be shown in the validity and reliability of the studies. On the other hand, if any studies show weakness in the process, then the quality of the studies will be inconsistent. To avoid this error, the validity and reliability of the studies must be looked at carefully. Due to this, the review stage is intended to find the best and strongest available evidence that has been shown. However, there are some variations and differences in study quality that may affect the final results. In order to get the best quality evidence, we will be developing a method for the standardised process of quality appraisal and working together as a team to decrease individual bias of the paper by using the guidelines of the National Health Services Centre for Review and Dissemination at University of York (https://www.york.ac.uk/crd)

\subsection{Data Synthesis}

In order to summarise the systematic review finding, the final decision on how to present the results was made at the last stage of data summarisation. Structural coding, categories, and themes related to the research purpose were narrated and analysed using MAXQDA 2020. Then thematic analysis was used to reveal the systematic findings. 


\section{Results}

\subsection{Search Results}

Figure 2 depicted the search process and results. In the first round of searching, eighty-six articles were found on those specific databases. No relevant article was found in reference lists. Title and abstract screening were used to exclude irrelevant articles such as study focusing on other mental disorders. Sixty-four articles, therefore, were excluded due to irrelevant titles and contents. Moreover, fourteen articles were excluded because of duplication. Thus, only eight articles were included for the analysis.

\begin{tabular}{|c|c|c|}
\hline Identitication & $\begin{array}{c}\text { The total of the first round of the screening from } 4 \\
\text { databases }(\mathrm{n}=86): 31 \text { (Psy INFO) }+30 \text { (MEDLINE) } \\
13 \text { (EBSCOhost) }+12 \text { (CINAHL Complete) }\end{array}$ & \\
\hline \multirow{3}{*}{ Screening } & & $\begin{array}{l}\text { Excluded by irrelevant titles and } \\
\text { abstract }(n=64)\end{array}$ \\
\hline & The total of the second round of the screening $(n=22)$ & \\
\hline & F & Excluded by duplication $(n=14)$ \\
\hline Included & $\begin{array}{l}\text { Total selected studies }(\mathrm{n}=8) \text { : I RCT, l qualitative } \\
\text { study, and } 6 \text { cross-sectional studies }\end{array}$ & \\
\hline
\end{tabular}

Figure 2. The Process of Study Selection

\subsection{Description of Included Studies}

Eight studies that were included for analysis published from four countries: Ethiopia $(n=3)$, France $(n=2)$, Bulgaria $(\mathrm{n}=2)$, and Spain $(\mathrm{n}=1)$. These were published from 2010 to 2020 in different journals (see Table 1).

Table 2. Summary Characteristics of Included Studies

\begin{tabular}{|c|c|c|c|c|c|}
\hline Author & Year & Country & $\begin{array}{l}\text { General } \\
\text { inclusion/exclusion } \\
\text { criteria }\end{array}$ & Samples & $\begin{array}{l}\text { Factors associated } \\
\text { with non-adherence }\end{array}$ \\
\hline $\begin{array}{l}\text { Dassa, Boyer, Benoit, } \\
\text { Bourcet, Raymondet, } \\
\text { and Bottai }\end{array}$ & 2010 & France & Meet criteria & $\begin{array}{l}291 \text { patients with } \\
\text { schizophrenia }\end{array}$ & $\begin{array}{l}\text { Duration of untreated psychosis, lack } \\
\text { of insight and a low level of } \\
\text { therapeutic alliance }\end{array}$ \\
\hline $\begin{array}{l}\text { Desalegn, Girma, and } \\
\text { Abdeta }\end{array}$ & 2020 & Ethiopia & Meet criteria & $\begin{array}{l}352 \text { patients with } \\
\text { schizophrenia }\end{array}$ & $\begin{array}{l}\text { Living in a rural-areas, current } \\
\text { substance use, duration of treatment } \\
\text { and polypharmacy }\end{array}$ \\
\hline Murru et al. & 2012 & Spain & Meet criteria & $\begin{array}{l}76 \text { patients with } \\
\text { schizophrenia }\end{array}$ & $\begin{array}{l}\text { Non-adherence associated to an } \\
\text { affective course of illness }\end{array}$ \\
\hline $\begin{array}{l}\text { Tareke, Tesfaye, } \\
\text { Amare, Belete, and } \\
\text { Abate }\end{array}$ & 2018 & Ethiopia & Meet criteria & $\begin{array}{l}423 \text { patients with } \\
\text { schizophrenia }\end{array}$ & $\begin{array}{l}\text { Non-adherence related to patients' } \\
\text { residency }\end{array}$ \\
\hline $\begin{array}{l}\text { Teferra, Hanlon, } \\
\text { Beyero, Jacobsson, } \\
\text { and Shibre }\end{array}$ & 2013 & Ethiopia & Meet criteria & $\begin{array}{l}24 \text { patients with } \\
\text { schizophrenia }\end{array}$ & $\begin{array}{l}\text { Poor patients tended to stop taking } \\
\text { antipsychotics }\end{array}$ \\
\hline Tinland et al. & 2017 & France & Meet criteria & $\begin{array}{l}218 \text { homeless } \\
\text { patients with } \\
\text { schizophrenia }\end{array}$ & $\begin{array}{l}\text { Gender, having more subjective } \\
\text { negative side effects and worse } \\
\text { attitudes toward psychotropic } \\
\text { medication }\end{array}$ \\
\hline
\end{tabular}




\begin{tabular}{|c|c|c|c|c|c|}
\hline $\begin{array}{l}\text { Vassileva, Milanova, } \\
\text { and Asan }\end{array}$ & 2014 & Bulgaria & Meet criteria & $\begin{array}{lr}226 & \text { homeless } \\
\text { patients } & \text { with } \\
\text { schizophrenia } & \end{array}$ & $\begin{array}{l}\text { Attitude toward medication, severity } \\
\text { of positive symptoms and the ability } \\
\text { to recognise psychotic symptoms }\end{array}$ \\
\hline Yalamova & 2015 & Bulgaria & Meet criteria & $\begin{array}{l}45 \text { homeless patients } \\
\text { with schizophrenia }\end{array}$ & $\begin{array}{l}\text { The frequency of admission from the } \\
\text { previous year was associated with the } \\
\text { non-adherence to medication }\end{array}$ \\
\hline
\end{tabular}

\subsection{Factors Related to Medication Nonadherence in Patients with Schizophrenia}

Content analysis was conducted to summarize research findings. The results were narrated into four main themes, namely individual characteristics, cognitive appraisal, social influence, and health-care service (see Table 3).

Table 3. Themes and Sub-Themes of Factors Related to Medication Nonadherence in Patients with Schizophrenia

\begin{tabular}{|c|c|c|}
\hline Themes & Sub-Themes & Factors \\
\hline \multirow{13}{*}{ Individual characteristics } & Gender & Being women (2) \\
\hline & Education & Having a high school diploma or less (2) \\
\hline & Poverty & Lacking food (2) \\
\hline & Residency & Living in a rural area (2) \\
\hline & \multirow{4}{*}{ Substance use } & Smoking tobacco (2) \\
\hline & & Chewing khat (2) \\
\hline & & Drinking alcohol drinks (3) \\
\hline & & Taking amphetamine-like substance (1) \\
\hline & \multirow{5}{*}{ Medical history } & Having a high number of mental illness hospitalization(3) \\
\hline & & Having positive symptoms (1) \\
\hline & & Having comorbid physical illness (4) \\
\hline & & Having a high number of mental illness hospitalization(3) \\
\hline & & Having positive symptoms (1) \\
\hline \multirow{4}{*}{ Cognitive appraisal } & \multirow{3}{*}{ Perception of illness } & Having anosognosia (1) \\
\hline & & Feeling guilty of missing appointment (1) \\
\hline & & Perceiving stigma of mental illness (2) \\
\hline & Attitudes toward medication & $\begin{array}{l}\text { Perceiving alienness of long-term medication } \\
\text { administration (1) }\end{array}$ \\
\hline \multirow{4}{*}{ Social influence } & \multirow{4}{*}{ Caregivers' attitudes } & Social stigma (2) \\
\hline & & Acute illness perspective (1) \\
\hline & & Dissatisfaction with mental health-care service (1) \\
\hline & & Negative social relationship (1) \\
\hline \multirow{6}{*}{ Health-care service } & Family support & Lack of family support (5) \\
\hline & \multirow{3}{*}{ Medication and its side effect } & Taking prescribed typical antipsychotics (3) \\
\hline & & Taking polypharmacy (1) \\
\hline & & Facing strong side effects of antipsychotics (1) \\
\hline & \multirow{2}{*}{ Duration for Treatment } & Post-discharge follow-up (2) \\
\hline & & Taking antipsychotics more than 5 years (1) \\
\hline
\end{tabular}


Having long untreated psychosis (1)

Having low number of attending psychosocial rehabilitation (1)

Perceiving negative response to patients who miss the

Health-care providers appointment (1)

Denying contacting mental health-care providers (1)

Having long waiting time in mental health outpatient

Healthcare system clinic (1)

Fixed appointment scheduling (1)

\section{Discussion}

In the current systematic review, factors relating to medication non-adherence in patients with schizophrenia were identified into four themes: individual characteristics, cognitive appraisal, social influence, and health-care service. Individual characteristics of patients with schizophrenia were important determinants of medication non-adherence. Women with schizophrenia tended to face severe side effects of antipsychotics and were less likely to admit their mental illness more than men; therefore, the increasing rate of medication non-adherence was found in women patients (Tinland et al., 2017). This was congruent with Desai and Nayak (2019) revealed that the prevalence of medication non-adherence in women with schizophrenia was approximately four times higher than those of men. Not only gender had an association with medication non-adherence in schizophrenia patients but also educational attainment. The present study found that these particular patients who earned a high school diploma or less were more likely to be non-adherent to medication, compared to those who graduated bachelor's degree and higher (Vassileva et al., 2014). It was consistent with previous studies, patients with schizophrenia who attended school less than 12 to 15 years had higher likelihood to fail medication adherence compared to those who attended school more than 15 years (Desai \& Nayak, 2019; Hastings, Hohmann, Jeminiwa, Hansen, Qian, \& Garza, 2021). The relationship between education attainment and medication adherence could be explained by health literacy. Patients who had a higher level of health literacy were prone to adhere to their medication regimens compared to those with lower health literacy (Miller, 2016). However, little is known about health literacy and medication adherence in patients with mental illness, especially schizophrenia.

The other two individual factors of patients with schizophrenia were poverty and residency. Teferra et al. (2013) explained that poor patients tended to stop taking antipsychotics because those pills made them desire to eat more foods. Since they lacked food, they denied continuing their medication (Teferra et al., 2013). This factor was important because even if schizophrenia patients were willing to adhere to their medication, they were forced to stop taking medication to prevent excessive hunger. Medication non-adherence was also related to schizophrenia patients' residency in which patients who lived in the rural area reported a higher rate of medication non-adherence (Tareke et al., 2018). Similarly, Leonard (2021) explained that schizophrenia patients living in rural areas were less likely to comply with their medication because they had negative attitudes toward medication. Since patients have different determinants of well-being and illness, providing appropriate care for individuals is crucial.

Substance use was one of determining factors for medication adherence in patients with schizophrenia. These patients who were using a substance such as tobacco, alcohol drinks, kat, or amphetamine were prone to denial of their prescribed medication (Tareke et al., 2018; Teferra et al., 2013). In the meantime, patients' caregivers skipped medication if they saw that their patients were drunk (Teferra et al., 2013). Therefore, substance use should be considered an essential facet of the overall medical history to prevent patients from taking medication and increase relapse. In order to assess the likelihood of medication non-adherence in these particular patients, nurses must ask schizophrenia patients or their caregivers regarding the number of mental illness hospitalization, recurrent positive symptoms, and comorbid physical illness. These three factors were negatively associated with medication adherence in which schizophrenia patients who were admitted to psychiatric hospitals frequently in the previous year tended to fail on medication adherence (Dassa et al., 2010; Vassileva et al., 2014; Yalamova, 2015). The main causes of hospitalization in these patients may be due to recurrent positive symptoms and comorbid physical illness. Positive symptoms recurrence indicated that patients might stop or discontinue their medication (Kikkert \& Dekker, 2017; Vassileva et al., 2014). Meanwhile, schizophrenia patients who had comorbid physical illnesses such as diabetes, hypertension, and cardiovascular disease tended to terminate taking polymedication (Desalegn et al., 2020; MacEwan, Silverstein, Shafrin, Lakdawalla, Hatch, \& Forma, 2018). Evidently, re-hospitalization, relapse, and medication non-adherence were related to mental health-care services. 
Patients who suffered from typical antipsychotics and polypharmacy side effects were 0.5 and 2 times more likely to stop their prescribed medication, respectively (Dassa et al., 2010; Tereke et al., 2018). In the meantime, the increasing rate of medication non-adherence in patients with schizophrenia who took antipsychotics more than five years was two times higher than those of who took medication less than five years (Tereke et al., 2018). The higher prevalence rate of medication non-adherence also found in patients who missed their first post-discharge follow-up and psychosocial rehabilitation so that they had long duration of untreated mental illness (Dassa et al., 2010; Tereke et al., 2018). These may influence by three main factors that were health-care providers, health-care systems, and patients' cognitive appraisal. Teferra et al. (2013) claimed that schizophrenia patients were afraid of negative response from health-care providers if they missed the appointments. Teferra et al. (2013) mentioned that patients complained about rigorous appointment scheduling and long waiting time in mental health outpatient clinic. Therefore, patients decided to stop their medication rather than contact health-care providers.

However, patients' perceptions of their mental illness were significantly important than other factors. Medication non-adherence was highly reported in patients who had negative perceptions, such as the perceived stigma of mental illness and alienness of long-term medication administration (Dassa et al., 2010; Teferra et al., 2013). While patients who lacked illness insight tended to ignore taking medication because they declined to accept being mentally ill (Dassa et al., 2010; Kikkert \& Dekker, 2017; Teferra et al., 2013). Dealing with schizophrenia patients who had a lower level of insight and a higher level of stigma was challenging for nurses. Therefore, nurses should establish interventions for improving patients' self-awareness and diminishing self-stigma. In doing this, nurses can not provide care for these patients alone. Nurses should allow patients' caregivers or family members involved in intervention because patients' caregivers or family members had both positive and negative influences on patients' medication adherence (Teferra et al., 2013; Vassileva et al., 2014). Kretchy, Osafo, Agyemang, Appiah, and Nonvignon (2018) revealed that stressful caregivers were less likely to involve in providing medication for schizophrenia patients. Whereas caregivers who perceived higher levels of social stigma and stress tended to ignore taking care of schizophrenia patients, which increased the likelihood of medication non-adherence (Kretchy et al., 2018; Teferra et al., 2013; Vassileva et al., 2014). On the other hand, family members who engaged in taking patients for outpatient clinic appointments and providing medication could help their schizophrenia patients comply with medication (Teferra et al., 2013). Medication non-adherence is a multifaced problem that requires multidisciplinary corporation. Nurses can not solve this problem alone without patients' and their family members' involvement.

\section{Conclusion}

Per the present study's findings, schizophrenia patients' characteristics and cognitive appraisal, including social influence and health-care service, had significant relationships with medication non-adherence. These important factors, therefore, should be considered in order to establish appropriate intervention. Notably, community health nurses and psychiatric nurses in both primary and tertiary care settings play vital roles in providing care in community and inpatient wards. Psychiatric nurses should prepare patients and their caregivers to realize the importance of medication adherence and post-discharge appointment. Moreover, psychiatric nurses should communicate and refer patients' information to community health nurses for continuum care. Then community health nurses can follow-up and provide necessary care for patients and their caregivers. This collaboration between health-care professionals can enhance exceptional care and improve the quality of life in patients with schizophrenia.

\section{Competing Interests Statement}

This study did not receive financial support. None of the authors has a conflict of interest.

\section{References}

Ansah, A., Bamfo, H. D., \& Nkyi, A. K. (2021). Non-adherence to psychotropic medications among mentally ill patients at the Ankaful Psychiatric Hospital. Indian Journal of Health and Wellbeing, 12(1), 73-78.

Chukwujekwu, C., \& Adesokun, O. (2017). Prevalence of medication non-adherence among psychiatric patients in a tertiary hospital in Nigeria. Journal of Biosciences and Medicines, 5, 1-10. https://doi.org/10.4236/jbm.2017.54001

Dassa, D., Boyer, L., Benoit, M., Bourcet, S., Raymondet, P., \& Bottai, T. (2010). Factors associated with medication non-adherence in patients suffering from schizophrenia: A cross-sectional study in a universal coverage health-care system. Australian and New Zealand Journal of Psychiatry, 44(10), 921-928. https://doi.org/10.3109/00048674.2010.493503.

Department of Mental Health. (2019). National mental health development plan no. 1. Nonthaburi, Thailand. 
Department of Mental Health.

Desai, R., \& Nayak, R. (2019). Effects of medication non-adherence and comorbidity on health resource utilization in schizophrenia. Journal of Managed Care and Specialty Pharmacy, 25(1), 37-46. https://doi.org/10.18553/jmcp.2019.25.1.037

Desalegn, D., Girma, S., \& Abdeta, T. (2020). Quality of life and its association with current substance use, medication non-adherence and clinical factors of people with schizophrenia in southwest Ethiopia: A hospital-based cross-sectional study. Health and Quality of Life Outcomes, 18(1), 82-82. https://doi. org/10.1186/s12955-020-01340-0

Hastings, T. J., Hohmann, N. S., Jeminiwa, R., Hansen, R. A., Qian, J., \& Garza, K. B. (2021). Perceived appropriateness of medication adherence incentives. Journal of Managed Care \& Specialty Pharmacy, 27(6), $772-778$.

Holly, C., Salmond, S., \& Saimbert, M. (2017). Comprehensive systematic review for advanced practice nursing, second edition ( $2^{\text {nd }}$ ed.). Springer.

Kikkert, M. J., \& Dekker, J. (2017). Medication adherence decisions in patients with schizophrenia. The Primary Care Companion for CNS Disorders, 19(6), 17n02182. https://doi.org/10.4088/PCC.17n02182

Kretchy, I. A., Osafo, J., Agyemang, S. A., Appiah, B., \& Nonvignon, J. (2018). Psychological burden and caregiver-reported non-adherence to psychotropic medications among patients with schizophrenia. Psychiatry Research, 259, 289-294. https://doi.org/10.1016/j.psychres.2017.10.034

Leonard, K. (2021). Psychotropic medication adherence and associated factors among adult patients with schizophrenia [Master's thesis, Lithuanian University of Health Science]. https:/www.lsmuni.lt/ cris/handle/20.500.12512/110493

MacEwan, J. P., Silverstein, A. R., Shafrin, J., Lakdawalla, D. N., Hatch, A., \& Forma, F. M. (2018). Medication adherence patterns among patients with multiple serious mental and physical illnesses. Advances in Therapy, 35(5), 671-685. https://doi.org/10.1007/s12325-018-0700-6

Miller, T. A. (2016). Health literacy and adherence to medical treatment in chronic and acute illness: A meta-analysis. Patient Education and Counseling, 99(7), 1079-1086. https://doi.org/10.1016/j.pec.2016.01.020.

Murru, A., Pacchiarotti, I., Nivoli, A. M. A., Bonnin, C. M., Patrizi, B., Amann, B., Vieta, E., \& Colom, F. (2012). Rates and clinical correlates of treatment non-adherence in schizoaffective bipolar patients. Acta Psychiatrica Scandinavica, 125(5), 412-418. https://doi.org/10.1111/j.1600-0447.2012.01837.x

Saengpak, C., Tungpunkom, P., \& Kitsumban, V. (2020). Effect of adherence therapy on medication adherence among persons with schizophrenia in community. Nursing Journal, 44(1), 137-148.

Sigrúnarson, V., Gråwe, R. W., Lydersen, S., \& Morken, G. (2017). Predictors of long-term use of psychiatric services of patients with recent-onset schizophrenia: 12 years follow-up. BMC Psychiatry, 17(1), 18-18. https://doi.org/10.1186/s12888-016-1186-X.

Suntarowit, N., Wijitphanya, A., \& Inkunthum, P. (2020). Effects of health promotion program on health behaviors for medication adherence of persons with schizophrenia. The Journal of Psychiatric Nursing and Mental Health, 34(2), 153-168.

Tareke, M., Tesfaye, S., Amare, D., Belete, T., \& Abate, A. (2018). Antipsychotic medication non-adherence among schizophrenia patients in central Ethiopia. The South African Journal of Psychiatry, 24(1), 1-6. https://doi.org/10.4102/sajpsychiatry.v24i0.1124

Teferra, S., Hanlon, C., Beyero, T., Jacobsson, L., \& Shibre, T. (2013). Perspectives on reasons for non-adherence to medication in persons with schizophrenia in Ethiopia: A qualitative study of patients, caregivers and health workers. BMC Psychiatry, 13(1), 168-168. https://doi.org/10.1186/1471-244X-13-168

The University of York. (2003). Retrieved from_https://www.york.ac.uk/crd

Tinland, A., Zemmour, K., Auquier, P., Boucekine, M., Girard, V., Loubière, S., ... \& Boyer, L. (2017). Homeless women with schizophrenia reported lower adherence to their medication than men: Results from the french housing first experience. Social Psychiatry and Psychiatric Epidemiology, 52(9), 1113-1122. https://doi.org/10.1007/s00127-017-1411-z

Vassileva, I., Milanova, V., \& Asan, T. (2014). Predictors of medication non-adherence in Bulgarian outpatients 
with schizophrenia. Community Mental Health Journal, 50(7), 854-861. https://doi.org/10.1007/s10597-014-9697-8

Velligan, D. I., Sajatovic, M., Hatch, A., Kramata, P., \& Docherty, J. (2017). Why do psychiatric patients stop antipsychotic medication? A systematic review of reasons for non-adherence to medication in patients with serious mental illness. Patient Preference and Adherence, 11, 449-468. https://doi.org/10.2147/PPA.S124658.

World Health Organization [WHO]. (2019). Mental disorders. Retrieved from https://www. who.int/newsroom/fact-sheets/detail/mental-disorders

Yalamova, I. (2015). Post-discharge medication adherence in schizophrenia. Archives of Psychiatry and Psychotherapy, 17(4), 39-47. https://doi.org/10.12740/APP/60513

Yeisen, R. A. H., Bjornestad, J., Joa, I., Johannessen, J. O., \& Opjordsmoen, S. (2017). Experiences of antipsychotic use in patients with early psychosis: A two-year follow-up study. BMC Psychiatry, 17(1), 299-299. https://doi.org/10.1186/s12888-017-1425-9

\section{Copyrights}

Copyright for this article is retained by the author(s), with first publication rights granted to the journal.

This is an open-access article distributed under the terms and conditions of the Creative Commons Attribution license (http://creativecommons.org/licenses/by/4.0/). 